\title{
Remarkable Changes in the Plasma Levels of Pituitary Protein "7B2" during Childhood
}

\author{
HARUO IGUCHI, YUICHI NIIDA, SHOICHI NATORI, NAOKI TAKAYANAGI, HITOSHI KOHNO, \\ KENICHI KATO, AND HAJIME NAWATA \\ Department of Biochemistry, National Kyushu Cancer Center, Fukuoka 815, Japan [H.I.]; Department of \\ Pediatrics, Sapporo Medical College, Sapporo 060, Japan [Y.N., N.T.]; Third Department of Internal Medicine, \\ Faculty of Medicine, Kyushu University, Fukuoka 812, Japan [S.N., K.K., H.N.]; and Department of \\ Endocrinology, Fukuoka Children's Hospital, Fukuoka 810, Japan [H.K.]
}

\begin{abstract}
We measured plasma immunoreactive (IR)$7 \mathrm{~B} 2$ concentrations in 96 children $(57$ males and $39 \mathrm{fe}-$ males) from the newborn period to $20 \mathrm{yr}$ of age. Plasma IR-7B2 concentrations in infants less than 2 yr of age (range $175-580 \mathrm{pg} / \mathrm{ml}, n=19$ ) were much higher than those in adults (range $20-138 \mathrm{pg} / \mathrm{ml}$ ). Plasma levels of IR7B2 decreased with age during childhood to reach the adult level at 15-20 yr. Significant negative correlations were found between plasma levels of IR-7B2 and dehydroepiandrosterone sulfate $(r=-0.4154, p<0.05, n=27)$, luteinizing hormone $(r=-0.4948, p<0.05, n=20)$ and follicle-stimulating hormone $(r=-0.4682, p<0.05, n=$ 20 ). The possibility of a relationship between the reduction of plasma IR-7B2 levels and pubertal development warrants attention. (Pediatr Res 24: 194-196, 1988)
\end{abstract}

Abbreviations

\author{
IR, immunoreactive \\ LHRH, luteinizing hormone releasing hormone \\ RIA, radioimmunoassay \\ GH, growth hormone \\ LH, luteinizing hormone \\ FSH, follicle-stimulating hormone \\ $T$, testosterone \\ $\mathbf{E}_{2}, 17-\beta$-estradiol \\ DHEA-S, dehydroepiandrosterone sulfate
}

$7 \mathrm{~B} 2$ is a protein recently isolated from porcine and human pituitary glands $(1,2) .7 \mathrm{~B} 2$ release from the pituitary gland and adrenal medulla of several species was demonstrated in vitro; hence, $7 \mathrm{~B} 2$ may be a secretory protein $(3-7)$. IR-7B2 is present in human plasma and the level is elevated in patients with chronic renal failure and patients with various endocrine tumors (8-10). We observed an age-related increase of plasma IR-7B2 levels in adults (20-87 yr of age) and very high levels in the cord blood $(8,11)$. In light of these observations, it seemed important to study plasma IR-7B2 levels during childhood. Thus, we measured plasma IR-7B2 concentrations in infants and children and partially characterized the molecular form, using gel permeation chromatography. In addition, we compared the IR-7B2 content in the pituitary glands of young and older persons.

Received December 10, 1987; accepted March 29, 1988.

Correspondence Dr. H. Iguchi, Department of Biochemistry, National Kyushu Cancer Center, 3-1-1 Notame, Minami-ku, Fukuoka 815, Japan.

Supported in part by Research Grant 60480273 and by a Grant-in-Aid for Special Project Research of Selected Intractable Neurological Disorders from the Ministry of Education, Science and Culture, Japan.

\section{MATERIALS AND METHODS}

Blood samples were taken from 96 subjects $(57$ males and 39 females, newborn to $20 \mathrm{yr}$ of age) into chilled glass tubes containing EDTA-2Na between $0800-1000 \mathrm{~h}$ after an overnight fast. After centrifugation, the plasma was stored at $-20^{\circ} \mathrm{C}$ until assay. Plasma levels of creatinine, blood urea nitrogen, bilirubin, glutamic oxaloacetic acid transaminase and glutamic pyruvic acid transaminase were within normal limits in all subjects. The stature and body weight of the subjects were within the mean \pm $2 \mathrm{SD}$ for age and struma was not found in all subjects. Pubertal stages of the subjects during puberty were corresponding to age.

LHRH testing was performed on six children with stature less than $-2 \mathrm{SD}$ of the mean height for age (four males and two females, 5-13 yr of age). Plasma GH levels were normal in these children. Blood samples were collected at $0,30,60,90$, and 120 min after an intravenous infusion of $2 \mu \mathrm{g} / \mathrm{kg} \mathrm{LHRH}$ (Tanabe Pharmaceutical Co., LTD, Osaka, Japan) through an indwelling catheter placed into a forearm vein. Plasma 7B2, LH, and FSH were measured in each sample by radioimmunoassay.

For measurements of pituitary tissue 7B2 concentrations, half pituitary glands were obtained at autopsy $1-4 \mathrm{~h}$ after death and stored at $-80^{\circ} \mathrm{C}$ until extraction. Three pituitary glands were obtained from children (less than 1 yr of age); 2 died of the respiratory distress syndrome and one of 18 -trisomy. Four pituitary glands were obtained from adults (35-91 yr of age); two died of lung cancer and two of cardiac desease. Pituitary metastasis was excluded in the cancer patients. The frozen pituitary glands were homogenized in $1 \mathrm{M}$ acetic acid containing $20 \mathrm{mM} \mathrm{HCl}$ with a Polytron. After boiling in a water bath for $10 \mathrm{~min}$, the homogenates were centrifuged at $1000 \times g$ for $20 \mathrm{~min}$ at $4^{\circ} \mathrm{C}$. An aliquot of the supernatant was stored at $-20^{\circ} \mathrm{C}$.

Gel permeation chromatography was performed on a Sephadex G-100 column $(95 \times 1.5 \mathrm{~cm})$ equilibrated with $1 \mathrm{M}$ acetic acid. A total of $2 \mathrm{ml}$ of pooled plasma from each of the two groups [younger group: $2.5 \pm 0.5$ yr old (mean $\pm \mathrm{SD}$ ), $n=3$; older group: $11.3 \pm 1.5 \mathrm{yr}$ old, $n=3$ ] was applied to the column and eluted with $1 \mathrm{M}$ acetic acid at a rate of $7 \mathrm{ml} / \mathrm{h}$ at $4^{\circ} \mathrm{C}$. Fractions $(1.3 \mathrm{ml})$ were collected, dried with a centrifugal concentrator (Taiyo VC-36, Tokyo, Japan), and reconstituted with $0.3 \mathrm{ml}$ of RIA buffer before assay.

Plasma IR-7B2 concentrations were measured using a specific RIA as described by Iguchi et al. (3). The 7B2-antiserum used was raised in rabbits against a synthetic fragment of 7B2 corresponding to residues 23-39 (a gift from Dr. S. R. Bloom, Hammersmith Hospital, London, England). The antiserum crossreacted $33 \%$, on a molar basis, with authentic porcine 7B2 but showed no cross-reaction with proopiomelanocortin-related peptides, arginine vasopressin, oxytocin, growth hormone, insulin, glucagon, somatostatin, pancreatic polypeptide, or secretin. The 
intra- and interassay coefficients of variation were 7.5 and $11.2 \%$, respectively $(n=5)$. A dilution curve of pooled plasma showed a parallel displacement with an RIA-standard curve (data not shown).

Plasma levels of GH, LH, FSH, T, $\mathrm{E}_{2}$, and DHEA-S were measured using RIA-kits (Eiken ICL, Daiichi RI Co., Tokyo, Japan; Diagnostic Products Corporation, Los Angeles, CA). Protein concentration was measured using a Bio-Rad Protein Assay Kit (Bio-Rad Laboratories, Richmond, CA) with bovine serum albumin as a standard.

Statistics. Correlations between plasma IR-7B2 concentrations and age and between plasma concentrations of IR-7B2 and DHEA-S, T, E 2 , LH, and FSH were determined by linear regression analysis, and the significance of variance in the calculated regression coefficient was assessed using Student's $t$-test. The difference of plasma IR-7B2 concentrations between the sexes was assessed using Wilcoxon's rank sum test applied to 2-yr age groupings of the children. Statistical analysis of the elevation of plasma IR-7B2 after LHRH infusion was performed using Student's $t$ test.

\section{RESULTS}

The mean $( \pm \mathrm{SD})$ concentration of IR-7B2 in infants less than $2 \mathrm{yr}$ of age was $394 \pm 96 \mathrm{pg} / \mathrm{ml}$ (range $175-580, n=19$ ), a value significantly higher than that in adults aged $20-87$ yr (20-138 $\mathrm{pg} / \mathrm{ml}, n=674$ ). As shown in Figure 1, a significant reduction of plasma IR-7B2 concentration was observed during childhood (male: $r=-0.7854, p<0.01, n=57$; female: $r=-0.6903, p<$ $0.01, n=39$ ) and the mean level of plasma IR-7B2 approximated the adult value at the age of 15-20 yr. There was no significant difference in plasma IR-7B2 concentrations between the sexes.

The responses of plasma IR-7B2 after the LHRH administration in six individuals are shown in Figure 2. We defined a $10 \%$ increase in plasma IR-7B2 concentrations (peak versus basal value) as a positive response, and by this criterion four of six children were responders. The mean $( \pm \mathrm{SD})$ percent increases of plasma IR-7B2 concentrations at 30,60, 90, and 120 min after the LHRH administration in four responders were $117 \pm 2.5$, $128 \pm 14.3,122 \pm 24.4$, and $110 \pm 15.6 \%$, respectively $(p<$

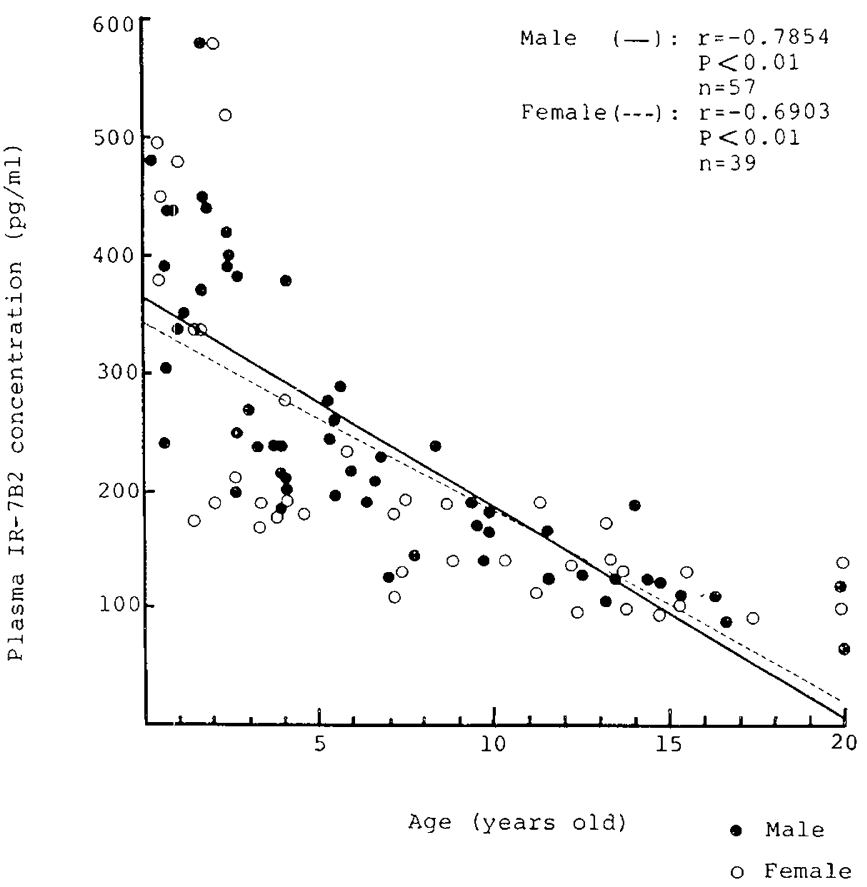

Fig. 1. Age-dependent reduction of plasma IR-7B2 concentrations during childhood.

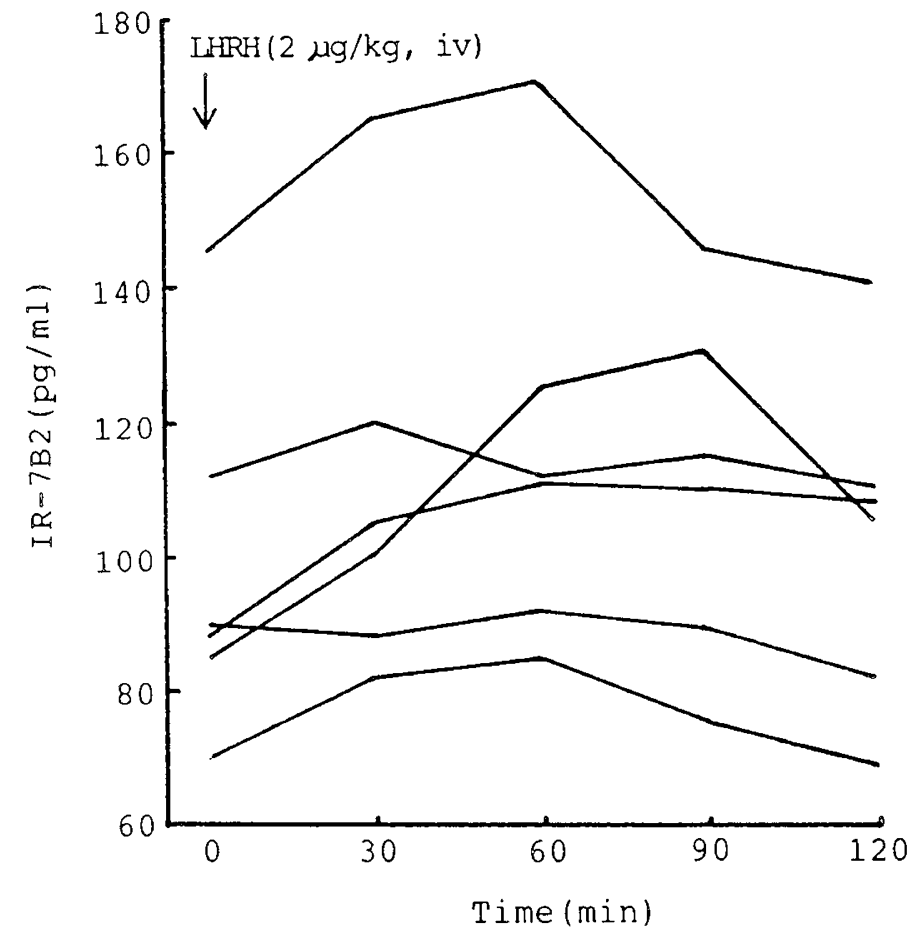

Fig. 2. Changes in plasma IR-7B2 concentrations after an intravenous infusion of LHRH $(2 \mu \mathrm{g} / \mathrm{kg})$ in six children.

$128 \pm 14.3,122 \pm 24.4$, and $110 \pm 15.6 \%$, respectively $(p<$ 0.01 at 30 and $60 \mathrm{~min}$ ). The average percent increase (peak versus basal value) of plasma IR-7B2 concentrations was less than the increase of plasma LH and FSH concentrations (data not shown).

The mean $( \pm \mathrm{SD})$ concentrations of IR-7B2 in the pituitary glands from children and from adults were $75.0 \pm 13.5$ and 58.3 $\pm 19.6 \mathrm{ng} / \mathrm{mg}$ protein, respectively. There was no significant difference between the pituitary IR-7B2 content in the children and in the adults.

Significant negative correlations were found between plasma levels of IR-7B2 and those of DHEA-S $(r=-0.4154, p<0.05$, $n=27)$, LH $(r=-0.4948, p<0.05, n=20)$ and FSH $(r=$ $-0.4682, p<0.05, n=20$ ) (Fig. 3). There were no significant correlations between plasma levels of IR-7B2 and those of $T$ and $\mathrm{E}_{2}$.

Figure 4 depicts the elution profiles on Sephadex G-100 of pooled plasma obtained from two groups of children. Most of the IR-7B2 eluted at an apparent mol. wt. of 20,000 in both the younger and older groups.

\section{DISCUSSION}

We noted an age-dependent reduction of plasma IR-7B2 concentrations during childhood. Natori et al. (8) reported an agedependent elevation of plasma IR-7B2 in normal human subjects. However, these data were obtained from subjects more than $20 \mathrm{yr}$ old. However, a high level of plasma IR-7B2 was noted in the cord blood of term infants at the time of normal delivery (11). These data suggested that the plasma IR-7B2 level decreases from a high value at birth to a lower adult level by $15-$ $20 \mathrm{yr}$ of age. Thereafter values increase slowly. During puberty we found significant negative correlations between the plasma levels of IR-7B2 and those of DHEA-S, LH, and FSH. 7B2 is localized in gonadotrophs of the anterior pituitary gland in the rat and an LHRH-induced release of IR-7B2 has been observed in cultured cells of the rat anterior pituitary gland $(5,12)$. We also noted an elevation of plasma IR-7B2 after LHRH administration in children. These findings suggest that $7 \mathrm{~B} 2$ may be 


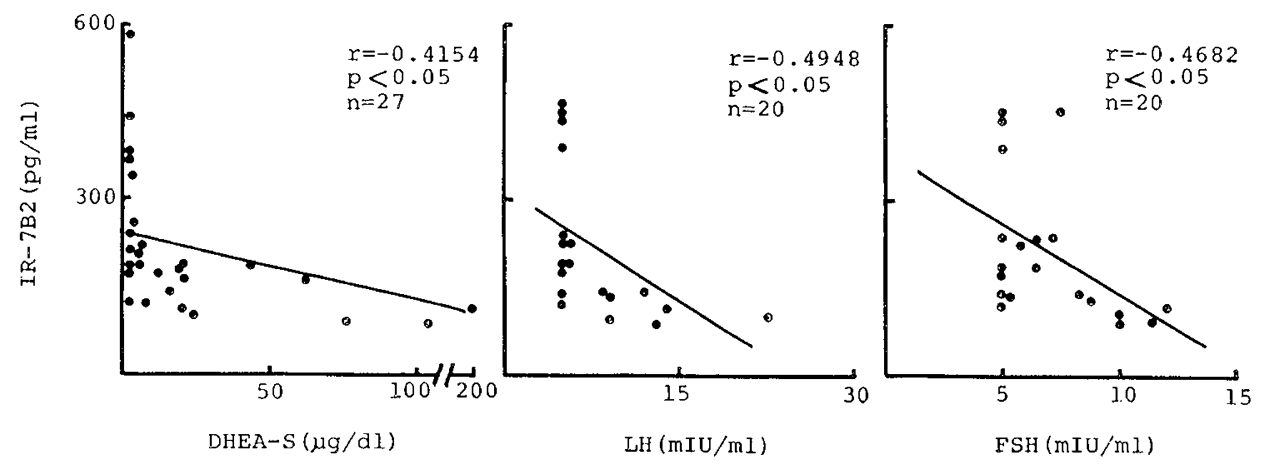

Fig. 3. Correlations between plasma levels of IR-7B2 and DHEA-S, LH, and FSH in children.

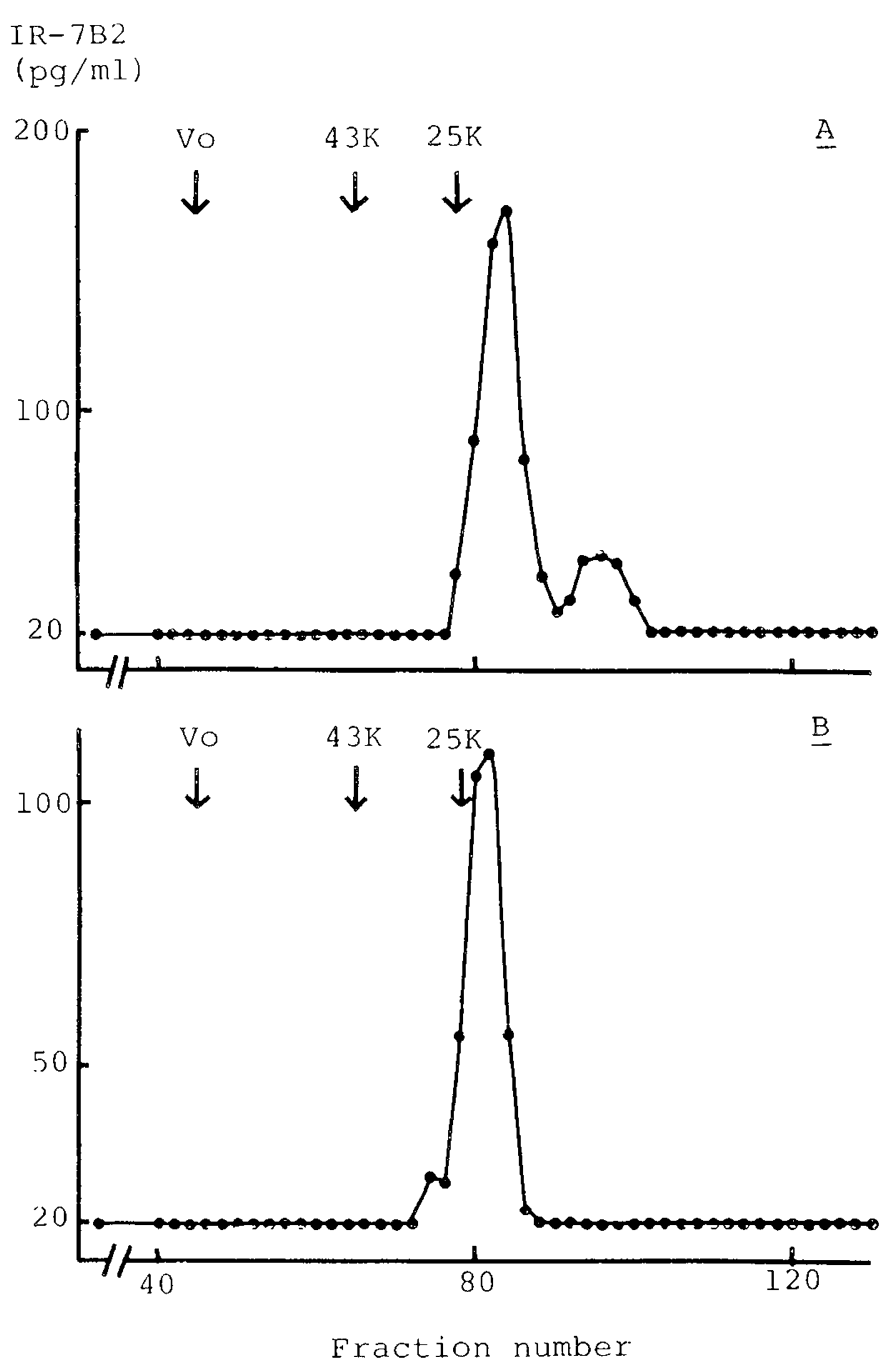

Fig. 4. Gel permeation chromatography of pooled plasma obtained from children on a Sephadex G-100 column $(95 \times 1.5 \mathrm{~cm}), A$, mean $( \pm$ SD) age $2.5 \pm 0.5, n=3 ; B$, mean age $11.3 \pm 1.5, n=3$. Molecular markers are indicated by arrows ( $V O$, catalase; $43 \mathrm{~K}$, ovalbumin; $25 \mathrm{~K}$, chymotrypsinogen A).

involved in pituitary-gonadal axis functions and may play a role in events related to puberty.

The origin of plasma IR-7B2 is unknown. The highest concentration of IR-7B2 was observed in the pituitary gland in the rat (3), and secretory characteristics of IR-7B2 were demonstrated in cultured cells of the rat anterior pituitary gland $(3,5)$. These observations led to the hypothesis that the majority of plasma IR-7B2 originates from the anterior pituitary gland. Marcinkiew- icz et al. (13) found in the anterior pituitary gland that the immunocytochemical staining of IR-7B2 was more intense in neonatal and young rats than in adult animals. The age-dependent reduction of plasma IR-7B2 may relate to a decrease in IR$7 \mathrm{~B} 2$ content in the anterior pituitary gland. However, we did not find a significant difference between the pituitary IR-7B2 content in children and adults.

Acknowledgments. The authors are deeply grateful to Dr. S. R. Bloom (Hammersmith Hospital, London, England) for the kind supply of a 7B2-antiserum, and Dr. M. Chrétien (Clinical Research Institute of Montreal, Montreal, Canada) for providing the synthetic fragment of 7B2 (7B2 23-39), M. Ohara for comments on the manuscript, and Y. Mori for secretarial help.

\section{REFERENCES}

1. Hsi KL, Seidah NG, DeSerres G, Chrétien M 1982 Isolation and $\mathrm{NH}_{2}$-terminal sequence of a novel porcine anterior pituitary polypeptide. FEBS Lett 147:261-266

2. Seidah NG, Hsi KL, DeSerres G, Rochemont J, Hamelin J, Antakly T, Cantin M, Chrétien M 1983 Isolation and $\mathrm{NH}_{2}$-terminal sequence of a highly conserved human and porcine pituitary protein belonging to a new superfamily. Archs Biochem Biophys 225:525-534

3. Iguchi H, Chan JSD, Seidah NG, Chrétien M 1984 Tissue distribution and molecular forms of a novel pituitary protein in the rat. Neuroendocrinology 39:453-458

4. Suzuki H, Tischler AS, Christofides ND, Chrétien M, Seidah NG, Polak JM, Bloom SR 1986 A novel pituitary protein (7B2)-like immunoreactivity is secreted by a rat phaeochromocytoma cell line (PC12). J Endocrinol 108:151-155

5. Deng JY, Chan JSD, Seidah NG, Chrétien M 1986 Specific release of a novel pituitary polypeptide, $7 \mathrm{~B} 2$, from rat anterior pituitary cells in vitro by luteinizing hormone-releasing hormone. Neuroendocrinology 44:373-377

6. Iguchi $H$, Natori $S$, Nawata $H$, Kato K, Ibayashi $H$, Chan JSD, Seidah NG, Chrétien M 1987 Presence of the novel pituitary protein '7B2' in bovine chromaffin granules: possible co-release of $7 \mathrm{~B} 2$ and catecholamine as induced by nicotine. J Neurochem 49:1810-1814

7. Natori S, Iguchi $H$, Nawata $H$, Kato $K$, Iayashi $H$, Nakagaki $H$, Chrétien $M$ 1988 Evidence for the release of a novel pituitary polypeptide (7B2) from the $\mathrm{GH}$-producing pituitary adenoma of patients with acromegaly. J Clin Endocrinol Metab 66:430-437

8. Natori S, Iguchi H, Nawata H, Kato K, Ibayashi H, Chrétien M 1987 Agerelated change in plasma concentration of 7B2 (a novel pituitary polypeptide) in normal humans. Life Sci 41:977-981

9. Suzuki H, Chatei MA, Williams SJ, Uttenthal LO, Facer P, Bishop AE, Polak JM, Bloom SR 1986 Production of pituitary protein 7B2 immunoreactivity by endocrine tumors and its possible diagnostic value. $\mathbf{J}$ Clin Endocrinol Metab 63:758-765

10. Iguchi H, Chan JSD, Seidah NG, Chrétien M 1987 Evidence for a novel pituitary protein (7B2) in human brain, cerebrospinal fluid and plasma: comparison of brain concentrations with Alzheimer's disease. Peptides 8:593-598

11. Iguchi $H$, Natori S, Nawata $H$, Kato K, Ibayashi H, Chan JSD, Seidah NG, Chrétien M 1987 Elevation of plasma 7B2 (a novel pituitary protein) in cord blood at obstetrical delivery and the possible correlation with GH. Life Sci 41:1921-1927

12. Marcinkiewicz M, Benjannet S, Seidah NG, Cantin M, Chrétien M 1985 Immunocytochemical localization of a novel pituitary protein $(7 \mathrm{~B} 2)$ within the rat brain and hypophysis. J Histochem Cytochem 33:1219-1226 